\title{
Optimization of Incorporated Prebiotics as Coating Materials for Probiotic Microencapsulation
}

\author{
Kun-NAN CHEN, Ming-Ju CHEN, Je-RUEI LIU, CHIN-WEN LIN, AND HSIN-Yi CHIU
}

\begin{abstract}
The purpose of this research was to improve probiotic microencapsulation using prebiotics and modern optimization techniques to determine optimal processing conditions, performance, and survival rates. Prebiotics (fructooligosaccharides or isomaltooligosaccharides), growth promoter (peptide), and sodium alginate were incorporated as coating materials to microencapsulate 4 probiotics (Lactobacillus acidophilus, Lactobacillus casei, Bifidobacterium bifidum, and Bifidobacterium longum). The proportion of the prebiotics, peptide, and sodium alginate was optimized using response surface methodology (RSM) to 1st construct a surface model, with sequential quadratic programming (SQP) subsequently adopted to optimize the model and evaluate the survival of microencapsulated probiotics under simulated gastric fluid test. Optimization results indicated that $1 \%$ sodium alginate mixed with $1 \%$ peptide and $3 \%$ fructooligosaccharides as coating materials would produce the highest survival in terms of probiotic count. The verification experiment yielded a result close to the predicted values, with no significant difference $(P>0.05)$. The storage results also demonstrated that addition of prebiotics in the walls of probiotic microcapsules provided improved protection for the active organisms. These probiotic counts remained at $10^{6}$ to $10^{7}$ colony-forming units (CFU)/g for microcapsules stored for $1 \mathrm{mo}$ and then treated in simulated gastric fluid test and bile salt test.
\end{abstract}

Keywords: microencapsulation, prebiotics, probiotics, response surface methodology

\section{Introduction}

$\mathrm{P}$ robiotics can be defined as living microbial supplements that can improve the balance of intestinal microorganisms (Fuller 1992). Good probiotic viability and activity are considered essential for optimal functionality (Mattila-Sandholm and others 2002). Furthermore, the ability of microorganisms to survive and multiply in the host strongly influences their probiotic benefits. The bacteria in the product should remain metabolically stable and active, surviving passage through the upper digestive tract in large numbers to produce beneficial effects when in the host intestine (Gilliland 1989).

Microencapsulation is a chemical or mechanical process in which particles containing an active ingredient are covered by a layer of another material, providing protection and controlled release of the primary ingredients as well as convenience to the ingredients. The survival and multiplication of probiotics in the host strongly affect their probiotic benefits. Many studies have shown low viability of probiotics in dairy products including yogurt and fermented milk (Iwana and others 1993; Shah and Lankaputhra 1997, Schillinger 1999). Protection of the probiotics has been proposed for various dairy fermentations, with microencapsulation in hydrocolloidal beads investigated for improving probiotic viability in both the food products and the intestinal tract (Prevost and Divies 1988; Lacroix and others 1990; Champagne and others 1992).

The composition of the wall usually influences the functional properties of the microcapsules (Hegenbart 1993). In the presence

MS 20040593 Submitted 9/2/04, Revised 10/28/04, Accepted 3/14/05. Authors M.-J. Chen, Liu, Lin, and Chiu are with Dept. of Animal Science, Natl. Taiwan Univ., Taipei, Taiwan, R.O.C. Author K.-N. Chen is with Dept. of Me chanical Engineering, Tung-Nan Inst. of Technology, Taipei, Taiwan, R.O.C. Direct inquiries to author M.-J. Chen (E-mail: cmj@ntu.edu.tw). of all coating materials, calcium alginate is favored because of its simplicity, nontoxicity, biocompatibility, and low cost (Sheu and Marshall 1993; Krasaekoopt and others 2004). Alginate is a linear heteropolysaccharide of D-mannuronic and L-guluronic acids extracted from various species of algae. The functional properties of alginate as a supporting material are strongly associated with the composition and sequence of L-guluronic and D-mannuronic acids. Divalent cations such as $\mathrm{Ca}^{2+}$ bind preferentially to the polymer of L-guluronic acid (Krasaekoopt and others 2003). The solubilization of the alginate gel by sequestering of calcium ions and release of the entrapped cells within the human intestine is another advantage for microencapsulated probiotics.

Prebiotics are nondigestible food ingredients that beneficially affect the host by selectively stimulating the growth and/or activity of 1 or a limited number of bacteria in the colon (Gibson and Roberfroid 1995). Bielecka and others (2002) have confirmed the appropriateness of combining prebiotics and probiotics, demonstrating greater effectiveness compared with probiotics alone. Accordingly, incorporation of prebiotics and calcium alginate as coating materials may provide better protection for probiotics in food and eventually the intestinal tract because of the potential for synergy between probiotics and prebiotics. Thus, the objectives of this study were to microencapsulate probiotics (Lactobacillus acidophilus, Lactobacillus casei, Bifidobacterium bifidum, and Bifidobacterium longum) using prebiotics (fructooligosaccharides [FOS] and isomaltooligosaccharides [IMO]), probiotic growth promoter (peptide from pancreatic digested casein), and alginate as coating materials and to evaluate the tolerance of the microencapsulated probiotics in milk and to gastric conditions. Furthermore, to determine the optimal ratio of the coating materials, which offered the best protection for the probiotics in microcapsules and to gastric condi- 
tions, the sequential quadratic programming technique was used to perform the optimization task.

\section{Materials and Methods}

\section{Experimental design}

The whole concept of this study included (1) experimental design using Box Behnkin Design (BBD), (2) microencapsulation of probiotics according to experimental design, (3) building response surface models and formulation of optimization model, (4) optimization using sequential quadratic programming, (5) verification experiments, and (6) storage test.

1. Experimental design using BBD. Experimental design preceded commencement of the trials. The BBD (Box and Behnkin 1960) is a 3-level design based on construction of a balanced incomplete block design. It was assumed that the viability of encapsulated probiotics is affected by the type and concentration of the coating materials, in this case alginate and 3 prebiotics (4 independent variables). A 4-variable BBD with 6 replicates at the center point was selected to build the response surface models (Table 1).

2. Microencapsulation of probiotics according to experimental design. . Culture conditions. Pure lyophilized cultures of B. longum (CCRC 14605), L. casei subsp. rhamnosus (CCRC 12321), B. bifidum (CCRC 11844), and L. acidophilus (CCRC 14079) were purchased from the Culture Collection and Research Center (Hsinchu, Taiwan, ROC). deMan, Rogosa, and Sharp (MRS) and lithium propionate MRS agar (LP-MRS) were used as the selective media for Lactobacillus spp and Bifidobacterium spp, respectively (Lapierre and others 1992).

Lactobacillus acidophilus and L. casei were transferred twice in Lactobacilli MRS broth (Difco, Le Poont de Claix, France) at $37^{\circ} \mathrm{C}$, whereas B. longum and B. bifidum were transferred twice in MRS broth containing $0.05 \%$ L-cysteine hydrochloride (Sigma, St. Louis, Mo., U.S.A.) in an anaerobic incubator and maintained at $40^{\circ} \mathrm{C}$. Cultures were harvested after $24 \mathrm{~h}$ by centrifugation $(3000 \times \mathrm{g}, 10 \mathrm{~min}$ at $4{ }^{\circ} \mathrm{C}$ ), washed and resuspended twice in saline solution. The final bacterial counts were adjusted to $10^{9}$ cells $/ \mathrm{mL}$.

b. Probiotic microencapsulation. Probiotic microcapsules were prepared according to the BBD shown in Table 1 (30 combinations of coating materials) by mixing $4 \%(\mathrm{v} / \mathrm{v})$ of culture concentrate $(1 \%$ each of L. acidophilus, L. casei, B. bifidum, and B. longum) with sodium alginate ( $1 \%$ to $3 \%$, Sigma) and the previously autoclaved $\left(121^{\circ} \mathrm{C}, 15 \mathrm{~min}\right.$ ) prebiotics (FOS, $0 \%$ to $3 \%$, Cheng-Fung Co, Taiwan; and IMO, $0 \%$ to $3 \%$, Ying-Yu Co., Taiwan), as well as peptides ( $0 \%$ to $1 \%$; pancreatic digested casein, Cheng-Fung Co). The extrusion technique of microencapsulation was used (Krasaekoopt and others 2004). After washing, $4 \%$ (v/v) of culture concentrate (1\% each of L. acidophilus, L. casei, B. bifidum, and B. longum) was mixed with $50 \mathrm{~mL}$ of $1 \%$ to $3 \%$ sodium alginate solution and sterilized at $121^{\circ} \mathrm{C}$ for $15 \mathrm{~min}$. The cell suspension was injected through a $0.11 \mathrm{~mm}$ needle into sterile $0.1 \mathrm{M} \mathrm{CaCl}_{2}$. The beads, approximately $0.5 \mathrm{~mm}$ in dia, were allowed to stand for $1 \mathrm{~h}$ for gelification and then rinsed with, and subsequently kept in, sterile $0.1 \%$ peptone solution at $4{ }^{\circ} \mathrm{C}$. Survival of the microencapsulated probiotics before and after simulated gastric fluid test (defined as responses) was determined. The 4 responses were defined as viability of Lactobacillus spp ( $L$. acidophilus + L. casei.) before simulated gastric fluid test (SGFT), viability of Bifidobacterium spp (B. longum + B. bifidum) before SGFT, viability of Lactobacillus spp after SGFT, and viability of Bifidobacterium spp after SGFT.

3. Modeling and optimization of coating materials in probiotic microcapsules. To carry out the response surface modeling, regression was performed on the experimental results to construct math- ematical models (Table 1). The models were then formulated as an objective function in an optimization problem and then solved using a sequential quadratic programming (SQP) approach to derive the optimal formulation for probiotic microcapsules. Both response surface modeling and SQP were used in a similar way according to the work by Chen and others (2003).

4. Model verification. After optimal processing conditions were found by the SQP, experiments based on the conditions were performed and repeated 3 times. The results were then analyzed using analysis of variance (ANOVA) from the SAS software package (SAS Inst. 1990), with Duncan's multiple range test for significance to detect differences between predicted values and observed values.

5. Survival of microencapsulated probiotics in milk. Mixed probiotics (1\% each of L. acidophilus, L. casei, B. bifidum, and B. longum) were added either as free cells to the milk (3.5\% milkfat, Natl. Taiwan Univ., Taipei, Taiwan) or as entrapped cells in microcapsules. The samples were stored at $4{ }^{\circ} \mathrm{C}$ for $14 \mathrm{~d}$, and the probiotic viability was determined.

6. Storage test. To understand the effect of prebiotics on the microencapsulated probiotics during storage, the viable cell counts for the encapsulated organisms were determined every $2 \mathrm{wk}$. In addition to the optimal probiotic microcapsules as determined from SQP, microcapsules with $1 \%$ and $3 \%$ alginate were also tested. The 3 microcapsules were immersed in aseptic water and stored at $4{ }^{\circ} \mathrm{C}$ for $3 \mathrm{mo}$, with the survival of the encapsulated probiotics in SGFT and bile salt conditions determined every $2 \mathrm{wk}$.

\section{Analysis methods}

1. Survival of encapsulated probiotics in SGFT and bile-salt conditions. Resistance to simulated gastric fluid was determined by adding $1 \mathrm{~g}$ of the microencapsulated bacteria into flasks containing $10 \mathrm{~mL}$ of the simulated gastric juice, which consisted of $0.3 \%$ pepsin (Sigma) and $0.5 \%$ sodium chloride (Nakalai, Kyoto, Japan) adjusted to $\mathrm{pH} 2.0$ with $1 \mathrm{NHCl}$. Resistance to bile salts was determined by adding microcapsules to the bile-salt solution, which consisted of $2 \%$ ox gall powder (Sigma). Both resistance treatments took place in agitated flasks $(100 \mathrm{rpm})$ at $25^{\circ} \mathrm{C}$ for $1 \mathrm{~h}$.

2. Determination of probiotic viability. To determine the probiotic viability count, the entrapped probiotics were released from the microcapsules according to the method of Sheu and Marshall (1993). One gram of the microcapsules was resuspended in $9 \mathrm{~mL}$ of phosphate buffer $(0.1 \mathrm{M}, \mathrm{pH}$ 7.0) followed by homogenization in a stomacher Seward Stomacker 400C, Brinkmann, Westbury, N.Y., U.S.A.) for $15 \mathrm{~min}$. The suitability of the media was tested by plating decimal dilutions of the probiotic cultures. Thus, a 1-g sample was decimally diluted into sterile peptone water $(0.1 \%)$, and then 0.1-mL aliquot dilutions were plated onto the different media, in triplicate. Plates of MRS agar were incubated aerobically for $72 \mathrm{~h}$ at $37^{\circ} \mathrm{C}$ to inhibit bifidobacteria. Plates of LP-MRS agar (GasPak System; Oxoid Unipath Ltd, Basingstoke, Hampshire, England) were incubated anaerobically $\left(72 \mathrm{~h}\right.$ at $37^{\circ} \mathrm{C}$ ) before enumeration of the bifidobacteria. The population, in colony-forming units (CFU), and the characteristics of the colonies were recorded for each medium.

3. Scanning electron microscopy. The microstructures of the microcapsules were observed by scanning electron microscope (SEM) according to the method of Lin and others (1999). Samples were fixed in $30 \mathrm{~g} / \mathrm{L}$ glutaraldehyde in $0.1 \mathrm{M}$ phosphate buffer ( $\mathrm{pH}$ 7.0) at $25^{\circ} \mathrm{C}$ for $4 \mathrm{~h}$. Then, the samples were washed in 3 changes of buffer and post-fixed with $10 \mathrm{~g} / \mathrm{L}$ osmium tetroxide in the same buffer at $25^{\circ} \mathrm{C}$ for $1 \mathrm{~h}$. After washing in distilled water, the samples were dehydrated in an ethanol series: $15 \%, 30 \%, 50 \%$, and $70 \%$ for 10 min each; $85 \%$ and $95 \%$ for 15 min each; and $100 \%$ for $1 \mathrm{~h}$. The 
Table 1-The variables and responses of experiment ${ }^{a}$

\begin{tabular}{|c|c|c|c|c|c|c|c|c|}
\hline \multirow[b]{3}{*}{ Block } & \multicolumn{4}{|c|}{ Variable } & \multicolumn{4}{|c|}{ Response } \\
\hline & \multirow{2}{*}{$\underset{\substack{X 1 \\
\text { Alginate }}}{\text { \% }}$} & \multirow{2}{*}{$\begin{array}{c}\text { X2 } \\
\text { Peptides } \\
(\%)\end{array}$} & \multirow{2}{*}{$\begin{array}{c}\text { X3 } \\
\text { FOS } \\
(\%)\end{array}$} & \multirow{2}{*}{$\begin{array}{c}\text { X4 } \\
\text { MOS } \\
(\%)\end{array}$} & \multirow[b]{2}{*}{$(\log C F U)$} & \multirow[b]{2}{*}{$(\log C F U)$} & \multicolumn{2}{|c|}{$\begin{array}{l}\text { Simulated gastric } \\
\text { fluid test }\end{array}$} \\
\hline & & & & & & & $\log C F U$ & $\log C F U$ \\
\hline 1 & 2.00 & 0.50 & 1.50 & 1.50 & 8.08 & 7.86 & 6.42 & 7.39 \\
\hline 1 & 2.00 & 0.50 & 1.50 & 1.50 & 8.18 & 7.90 & 6.44 & 7.43 \\
\hline 1 & 1.00 & 0.00 & 1.50 & 1.50 & 8.14 & 8.00 & 4.18 & 7.02 \\
\hline 1 & 2.00 & 0.50 & 0.00 & 3.00 & 8.16 & 8.01 & 6.42 & 7.43 \\
\hline 1 & 1.00 & 1.00 & 1.50 & 1.50 & 8.28 & 8.10 & 6.39 & 7.53 \\
\hline 1 & 2.00 & 0.50 & 0.00 & 0.00 & 7.97 & 7.87 & 5.25 & 7.56 \\
\hline 1 & 2.00 & 0.50 & 3.00 & 0.00 & 8.20 & 7.76 & 6.54 & 7.34 \\
\hline 1 & 3.00 & 1.00 & 1.50 & 1.50 & 8.13 & 8.05 & 6.65 & 7.41 \\
\hline 1 & 2.00 & 0.50 & 3.00 & 3.00 & 8.22 & 8.04 & 6.41 & 7.24 \\
\hline 1 & 3.00 & 0.00 & 1.50 & 1.50 & 7.96 & 7.63 & 5.12 & 7.07 \\
\hline 2 & 2.00 & 1.00 & 3.00 & 1.50 & 8.15 & 7.91 & 7.52 & 7.57 \\
\hline 2 & 1.00 & 0.50 & 1.50 & 3.00 & 8.15 & 8.03 & 7.09 & 7.41 \\
\hline 2 & 1.00 & 0.50 & 1.50 & 0.00 & 8.23 & 7.91 & 7.00 & 7.73 \\
\hline 2 & 2.00 & 1.00 & 0.00 & 1.50 & 8.13 & 8.00 & 7.12 & 7.15 \\
\hline 2 & 2.00 & 0.50 & 1.50 & 1.50 & 8.27 & 7.91 & 7.42 & 7.37 \\
\hline 2 & 2.00 & 0.00 & 0.00 & 1.50 & 8.02 & 7.57 & 5.35 & 7.06 \\
\hline 2 & 3.00 & 0.50 & 1.50 & 0.00 & 8.10 & 7.87 & 7.57 & 7.61 \\
\hline 2 & 2.00 & 0.50 & 1.50 & 1.50 & 8.20 & 7.54 & 7.51 & 7.30 \\
\hline 2 & 2.00 & 0.00 & 3.00 & 1.50 & 8.04 & 7.17 & 6.09 & 7.27 \\
\hline 2 & 3.00 & 0.50 & 1.50 & 3.00 & 8.10 & 7.60 & 7.52 & 7.44 \\
\hline 3 & 3.00 & 0.50 & 0.00 & 1.50 & 7.93 & 7.23 & 6.97 & 7.05 \\
\hline 3 & 2.00 & 0.00 & 1.50 & 0.00 & 8.01 & 7.37 & 7.60 & 7.55 \\
\hline 3 & 2.00 & 0.50 & 1.50 & 1.50 & 8.12 & 7.29 & 8.01 & 7.36 \\
\hline 3 & 2.00 & 0.50 & 1.50 & 1.50 & 8.15 & 7.70 & 8.08 & 7.76 \\
\hline 3 & 1.00 & 0.50 & 3.00 & 1.50 & 8.19 & 7.46 & 7.75 & 7.71 \\
\hline 3 & 2.00 & 1.00 & 1.50 & 3.00 & 8.07 & 7.75 & 8.10 & 7.60 \\
\hline 3 & 1.00 & 0.50 & 0.00 & 1.50 & 8.14 & 7.62 & 7.05 & 7.08 \\
\hline 3 & 3.00 & 0.50 & 3.00 & 1.50 & 8.00 & 7.57 & 7.99 & 7.36 \\
\hline 3 & 2.00 & 1.00 & 1.50 & 0.00 & 8.19 & 7.62 & 8.02 & 7.96 \\
\hline 3 & 2.00 & 0.00 & 1.50 & 3.00 & 8.00 & 6.91 & 7.45 & 7.45 \\
\hline
\end{tabular}

aCFU = colony-forming units; FOS = fructooligosaccharides; IMO = isomaltooligosaccharides .

bL $=$ Lactobacillus acidophilus + Lactobacillus casei

$\mathrm{cB}=$ Bifidobacterium longum + Bifidobacterium bifidum

resulting specimens were critical-point dried $\left(\mathrm{CO}_{2}\right.$ Critical Point Dryer Samdri-PVT-3B; Tousimis, Rockville, Md., U.S.A.). Eventually, the samples were fixed in stubs on a double-faced metallic tape and covered with a fine layer of gold (Ion Coater JJFC1100E; JEOL Ltd, Tokyo, Japan) while applying a current of $40 \mathrm{~mA}$, and observed using an SEM (JSM-6300, JEOL Ltd.).

\section{Results and Discussion}

\section{Response surface modeling}

The results presented in Table 1 for the viability of microencapsulated probiotics before and after SGFT were obtained immediately after extrusion. Response surface methodology (RSM) was used in the present work to develop a prediction model for establishing the optimal concentrations of 4 coating materials for the probiotic microcapsules. The responses, as linear, quadratic, and cubic functions of the variables, were tested for adequacy and fitness using ANOVA. Model analysis (Table 2) and the lack-of-fit test were used for selection of adequacy models, as outlined by Lee and others (2000), Weng and others (2001), and Chen and others (2004). Table 2 compares the validities of the linear, quadratic, and cubic models for the 4 responses according to their $\mathrm{F}$ values. A model with $P$ values $(P>\mathrm{F})$ below 0.05 was regarded as significant. The highest-order significant polynomial was selected. The lack-of-fit test was used to compare the residual and pure errors at replicated design points. The response predictor was discarded where lack of fit was significant, as indicated by a low probability value $(P>\mathrm{F})$. The model with no significant lack of fit was selected. Using ANOVA (Table 2), it was demonstrated that 3 linear survival models for Lactobacillus spp and Bifidobacterium spp before SGFT and Bifidobacterium spp after SGFT, and 1 cubic model for the survival of Lactobacillus spp after SGFT appeared to be the most accurate with no significant lack of fit. The 4 models are given as follows:

$$
\begin{gathered}
f_{k}=\beta_{0}+\sum_{i=1}^{n} \beta_{i} X_{i} \quad k=1,2,3 \\
f_{4}=\beta_{0}+\sum_{i=1}^{n} \beta_{i} X_{i}+\sum_{i=1}^{n} \beta_{i i} X_{i}^{2}+\sum_{i=1}^{n-1} \sum_{j=i+1}^{n} \beta_{i j} X_{i} X_{j}+\sum_{i=1}^{n} \beta_{i i i} X_{i}^{3} \\
+\sum_{i=1}^{n-1} \sum_{j=i+1}^{n} \beta_{i j} X_{i}^{2} X_{j}+\sum_{i=1}^{n-1} \sum_{j=i+1}^{n} \beta_{i j} X_{i} X_{j}^{2}+\sum_{i=1}^{n-2} \sum_{j=i+l k=j+1}^{n-1} \sum_{i j k}^{n} X_{i} X_{j} X_{k}
\end{gathered}
$$

where $n$ is the number of independent variables (that is, $n=4$ ); $f_{1}$, $f_{2}$, and $f_{3}$ are the survival of Lactobacillus spp and Bifidobacterium spp before SGFT and Bifidobacterium spp after SGFT, respectively; $f_{4}$ is survival of Lactobacillus spp after SGFT; $\beta$ s are regression coefficients; and $X s$ are the uncoded independent variables. The regression coefficients for the statistically significant models are presented in Table 3. The 3-level BBD design is incapable of forming the pure cubic terms (that is, $\beta_{i i i} \mathrm{X}_{i}^{3}$ in Eq. 2), with the coefficients presented in Table 3 confirming this fact. The 4 responses are then 
Table 2-Model analysis of the viability of lactic acid bacteria for storage (a) before simulated gastric fluid test (SGFT) and (b) after SGFT

(a) Before SGFT

\begin{tabular}{lccccc}
\hline & \multicolumn{2}{c}{$\mathbf{L}^{\mathbf{b}}$} & & \multicolumn{2}{c}{$\mathbf{B}^{\mathbf{c}}$} \\
\cline { 2 - 3 } \cline { 5 - 6 } Source & $\begin{array}{c}\text { Sum of } \\
\text { squares }\end{array}$ & $\boldsymbol{P}>\mathbf{F}$ & & $\begin{array}{c}\text { Sum of } \\
\text { squares }\end{array}$ & $\boldsymbol{P}>\mathbf{F}$ \\
\hline Mean & 1976.32 & - & & 1782.85 & - \\
Linear & $1.40 \times 10^{-1}$ & $0.0002^{* *}$ & & $7.70 \times 10^{-1}$ & $0.0013^{\star *}$ \\
Quadratic & $3.80 \times 10^{-2}$ & 0.5377 & & $3.20 \times 10^{-1}$ & 0.4090 \\
Cubic & $3.30 \times 10^{-2}$ & 0.5023 & & $2.00 \times 10^{-1}$ & 0.6494 \\
Residual & $2.00 \times 10^{-2}$ & - & & $1.60 \times 10^{-1}$ & - \\
\hline Total & 1976.56 & - & & 1785.44 & -
\end{tabular}

(b) After SGFT

\begin{tabular}{lccccc}
\hline & \multicolumn{2}{c}{$\mathbf{L}^{\mathbf{b}}$} & & \multicolumn{2}{c}{$\mathbf{B}^{\mathbf{c}}$} \\
\cline { 2 - 3 } \cline { 5 - 6 } Source & $\begin{array}{c}\text { Sum of } \\
\text { squares }\end{array}$ & $\boldsymbol{P}>\mathbf{F}$ & & $\begin{array}{c}\text { Sum of } \\
\text { squares }\end{array}$ & $\boldsymbol{P}>\mathbf{F}$ \\
\hline Mean & 1428.32 & - & 1645.88 & - \\
Linear & 7.31 & $0.0004^{* *}$ & & $5.20 \times 10^{-1}$ & $0.0292^{*}$ \\
Quadratic & 3.97 & $0.0161^{*}$ & & $5.00 \times 10^{-1}$ & 0.2185 \\
Cubic & 1.39 & $0.0006^{* *}$ & & $3.00 \times 10^{-1}$ & 0.2918 \\
Residual & $2.60 \times 10^{-2}$ & - & & $1.10 \times 10^{-1}$ & - \\
\hline Total & 1456.02 & - & 1647.43 & - \\
\hline
\end{tabular}

aModel analysis selects the highest order polynomial where the additional terms are significant. ${ }^{*}=$ Significant at $5 \%$ level; ${ }^{* *}=$ significant at $1 \%$ level.

$\mathrm{b} \mathrm{L}=$ Lactobacillus acidophilus + Lactobacillus casei

${ }^{\mathrm{C}} \mathrm{B}=$ Bifidobacterium longum + Bifidobacterium bifidum

combined into a composite function (CF) whose maximum can then be sought by optimization techniques.

$$
\mathrm{CF}=\left(f_{1} \times f_{2} \times f_{3} \times f_{4}\right)^{1 / 4}
$$

\section{Optimizing combinations of coating materials}

Because the composite function (Eq. 3) is a product of 3 linear functions and 1 cubic analog, it appears very likely that multiple local maxima exist. Therefore, a global optimization program consisting of a multi-start SQP was coded to search for the global optimum. The program generates a series of uniformly distributed random points for the initial search, and then SQP is applied to find the optimum based on each subsequent initial point. If the probability exceeds a preset value (99.99\% in this study), the global optimum is considered found. Otherwise, the next random initial point is generated and the SQP re-executed. After 24 sets of randomly generated initial points leading to optimal CF values (local optima) ranging from 7.85 to 8.17 , the global optimal CF was found to be 8.17 (99.99\% certainty). The global optimal CF values corresponded to $8.30 \log$ CFU for survival of Lactobacillus spp before SGFT; $8.01 \log$ CFU for survival of Bifidobacterium spp before SGFT; $8.12 \log$ CFU for survival of Lactobacillus spp after SGFT; and $7.80 \log$ CFU for survival of Bifidobacterium spp after SGFT. The highest optimal CF value (8.17) was attained for 11 of 24 sets, with the optimal points, $\mathrm{X} 1$ (alginate\%) $=1, \mathrm{X} 2($ peptides $\%)=1$, $\mathrm{X} 3(\mathrm{FOS} \%)=3$, and X4 (IMO) $=0$. The optimal combination of coating materials for probiotic microcapsules was $1 \%$ sodium alginate blended with $1 \%$ peptides, $3 \%$ FOS, and $0 \%$ IMO.

The reported concentrations of alginate used for gel formation vary from $1.5 \%$ to $2.5 \%$ with 0.05 to $1.5 \mathrm{M} \mathrm{CaCl}_{2}$ (Krasaekoopt and others 2003). In this study, concentrations of alginate within the range of $1 \%$ to $3 \%$ were tested because preliminary tests had shown that when blended with prebiotics it could improve probiotic mi-
Table 3-The coefficients of probiotic viability model (a) before simulated gastric fluid test (SGFT) and (b) after SGFT

(a) Before SGFT

\begin{tabular}{ccc}
\hline Coefficient & $\mathbf{L}^{\mathbf{a}}$ & $\mathbf{B}^{\mathbf{b}}$ \\
\hline$\beta 0$ & 8.17 & 7.71 \\
$\beta 1$ & -0.075 & -0.098 \\
$\beta 2$ & 0.13 & 0.46 \\
$\beta 3$ & 0.024 & -0.021 \\
$\beta 4$ & $-1.053 \times 10^{-3}$ & $-3.452 \times 10^{-3}$
\end{tabular}

(b) After SGFT

\begin{tabular}{ccc}
\hline Coefficient & $\mathbf{L}^{\mathbf{a}}$ & $\mathbf{B}^{\mathbf{b}}$ \\
\hline$\beta 0$ & 1.41 & 7.35 \\
$\beta 1$ & 3.53 & -0.045 \\
$\beta 2$ & 8.89 & 0.30 \\
$\beta 3$ & 1.35 & 0.065 \\
$\beta 4$ & -0.68 & -0.065 \\
$\beta 11$ & -0.83 & - \\
$\beta 22$ & -1.19 & - \\
$\beta 33$ & -0.23 & - \\
$\beta 44$ & 0.074 & - \\
$\beta 12$ & -5.89 & - \\
$\beta 13$ & 0.029 & - \\
$\beta 14$ & 0.65 & - \\
$\beta 23$ & -1.46 & - \\
$\beta 24$ & 0.81 & - \\
$\beta 34$ & -0.14 & - \\
$\beta 112$ & 1.34 & - \\
$\beta 113$ & 0.076 & - \\
$\beta 114$ & -0.17 & - \\
$\beta 122$ & 0.20 & - \\
$\beta 133$ & -0.093 & - \\
$\beta 223$ & -0.085 & - \\
$\beta 224$ & -0.74 & \\
$\beta 233$ & 0.48 &
\end{tabular}

$\mathrm{aL}=$ Lactobacillus acidophilus + Lactobacillus casei .

$\mathrm{b}_{\mathrm{B}}=$ Bifidobacterium longum + Bifidobacterium bifidum

croencapsulation. The optimal value found and subsequently used for the preparation of optimum microcapsules was $1 \%$ sodium alginate, which is lower than Krasaekoopt and others' findings (2003). Chandramouli and others (2004) attempted to improve the method of microencapsulation and found that the viability of the encapsulated bacteria in simulated gastric conditions increased with increased alginate gel concentration from $0.75 \%$ to $1.8 \%(\mathrm{w} / \mathrm{v})$. Our own findings were somewhat contradictory, however, with SQP analysis suggesting a relatively low level of sodium alginate (1\%). Furthermore, blending prebiotics with sodium alginate as coating materials for probiotic microencapsulation did improve organisms survival under SGFT.

A number of earlier studies have investigated the effects of peptides on human gut bacteria (Mitsuoka and others 1987; Dave and Shah 1998; Lourens-Hattingh and Viljoen 2001). Nitrogen sources, in the form of various peptides and amino acids, probably act by improving the viability of the bifidobacteria present in the gut (Lourens-Hattingh and Viljoen 2001). The present study confirmed the prebiotic effects of peptides. Fooks and others (1999) have revealed that IMO are very efficient prebiotic agents in that they are able to stimulate lactic microflora while facilitating elevated production of butyrate, believed to be a desirable metabolite in the gut. However, incorporation of IMO as coating materials for microcapsules did not improve probiotic survival in the current study.

To further depict the global optimization results, 3-D response surface plots were generated by fixing 2 of the 4 variables. Figure 1 shows 3 local maxima, including the global analog, in a CF response 
function produced for the values X2 (peptide) $=1$ and X3 $($ FOS $)=3$, while varying X1 (alginate) and X4 (IMO) within their boundaries. The optimization results clearly show that determination of the global optima depends on the initial search points for the response surface models.

\section{Experimental verification}

The optimal production conditions for wall composition were derived from SQP and verified by independent additional experiments. The optimal combination of coating materials for the probiotic microcapsules were $1 \%$ sodium alginate blended with $1 \%$ peptides, $3 \%$ FOS, and $0 \%$ IMO. Table 4 shows that the experimental values were very close $(P>0.05)$ to the predicted values for survival of Lactobacillus spp and Bifidobacterium spp before and after SGFT with no significant differences.

\section{Microstructure of probiotic microcapsules}

Scanning electron microscopy was used to examine the structure of the probiotic microcapsules. The probiotic microcapsules were in spherical shapes (Figure 2a and 2b) with groups of entrapped bacteria evident in the internal voids and surrounded by the matrix (Figure 2c and 2d). Sheu and Marshall (1993) have indicated that concentration of sodium alginate affects the structure of the microcapsules; higher concentrations produce a smoother surface. Similar results were found in our study. The probiotic microcapsules using $3 \%$ alginate have a smooth surface (Figure $2 \mathrm{~b}$ ) and relative small pores (Figure 2d), whereas optimum probiotic microcapsules using $1 \%$ sodium alginate (Figure 2 a) have a rough surface and markedly open and large pores (Figure 2c). Raising the sodium alginate concentration increases the number of binding sites for $\mathrm{Ca}^{2+}$ ions. Consequently, a more densely cross-linked gel structure is formed (Chandramouli and others 2004).

\section{Survival free and microencapsulated probiotics in milk}

Survival of probiotics entrapped in prebiotic microcapsules immersed in refrigerated milk for $2 \mathrm{wk}$ was significantly improved over that of free cells as shown in Table 5. Similar results have been re-

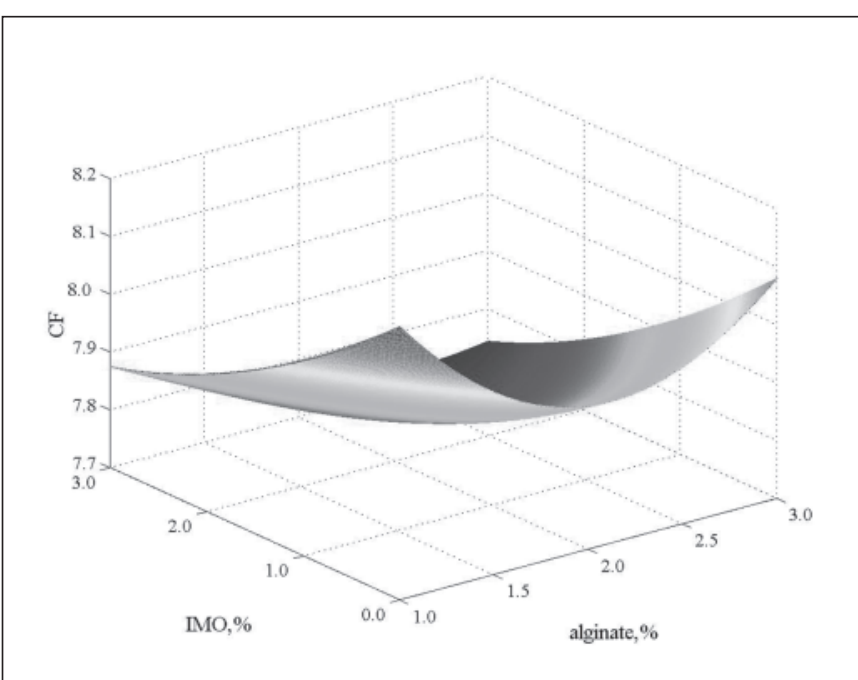

Figure 1-A response surface plot for survivability of probiotic microcapsules showing the effects of sodium alginate and isomaltooligosaccharides (IMO) for constant levels of peptides and fructooligosaccharides (FOS) (1\% and $3 \%$, respectively). CF = Composite Function.
Table 4-The validation of the optimal producing model (1\% alginate, $1 \%$ peptide, $3 \%$ FOS), recommended by SQP for probiotic microcapsules before and after simulated gastric fluid test ${ }^{\mathrm{a}}$

\begin{tabular}{lcclcc}
\hline & \multicolumn{2}{c}{ L $^{\mathbf{b}}(\log$ CFU/g) } & & \multicolumn{2}{c}{ B $^{\mathbf{c}}(\log$ CFU/g) } \\
\cline { 2 - 3 } \cline { 6 - 6 } & Pred $^{\mathbf{d}}$ & Exp $^{\mathbf{e}}$ & & Pred & Exp \\
\hline Before & 8.30 & 8.20 & & 8.01 & 7.86 \\
After & 8.12 & 7.97 & & 7.80 & 7.63 \\
\hline
\end{tabular}

${ }^{*} P<0.05$.

aCFU = colony-forming units; FOS = fructooligosaccharides; SQP = sequential quadratic programming.

$\mathrm{b} \mathrm{L}=$ Lactobacillus acidophilus + Lactobacillus casei.

$\mathrm{c} B=$ Bifidobacterium longum + Bifidobacterium bifidum

dPred $=$ predicted value.

exp = experimental value.

ported for probiotic microencapsulated in alginate microcapsules in yogurt (Sultana and others 2000; Adhikari and others 2003) and in fermented frozen dairy deserts (Shah and Ravula 2000). Hansen and others (2002) concluded that microencapsulation with calcium alginate is able to protect probiotics in food products.

\section{Storage tests}

To elucidate the effects of the inclusion of prebiotics in the walls of the microcapsules during storage, the probiotic microcapsults were immersed in aseptic water for $3 \mathrm{mo}$, and the survival of the organisms was measured every $2 \mathrm{wk}$. Results of the probiotic counts showed that, as might be expected, viability decreased with increasing storage period for all 3 microcapsule formulations (Figure 3). Probiotic counts for the optimal probiotic microcapsule were still $10^{5}$ to $10^{6} \mathrm{CFU} / \mathrm{g}$ after the 12 -wk storage in contrast to just $10^{2}$ to $10^{3}$ $\mathrm{CFU} / \mathrm{g}$ for those without the prebiotics. Thus, blending of prebiotics in the coating materials resulted in better protection for the encapsulated organisms during storage, relative to the prebioticfree variants. The microcapsules containing FOS and peptide can provide the carbon and nitrogen source for microencapsulated probiotics during storage.

The effects of wall materials and sodium alginate concentrations on viability of Lactobacillus spp and Bifidobacterium spp under sim-
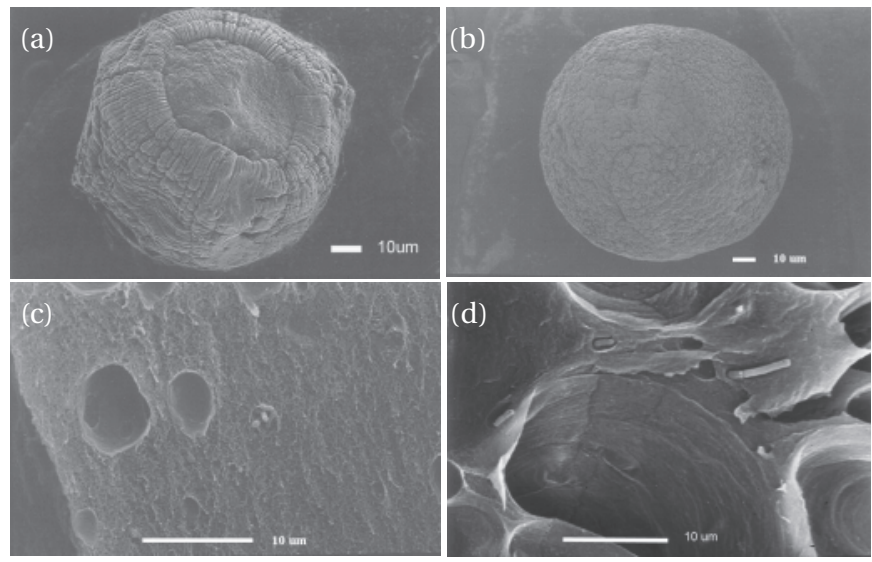

Figure 2-Microstructure of probiotic microcapsules: (a) whole unfractured microcapsules using $1 \%$ alginate, $1 \%$ peptide, and $3 \%$ fructooligosaccharides (FOS) as coating material; (b) whole unfractured microcapsules using $3 \%$ alginate as coating material; (c) fractured microcapsules using $1 \%$ alginate, $1 \%$ peptide, and $3 \%$ FOS as coating material; (d) fractured microcapsules using $3 \%$ alginate as coating material. 
Table 5-Survival in milk of free and microencapsulated probiotics during storage at $4^{\circ} \mathrm{C}$

\begin{tabular}{|c|c|c|c|c|c|}
\hline \multirow{2}{*}{$\begin{array}{l}\text { Probiotics culture } \\
(\log \text { CFU/g) }\end{array}$} & \multicolumn{5}{|c|}{ Storage period (d) } \\
\hline & 0 & 4 & 8 & 12 & 16 \\
\hline $\begin{array}{l}\text { Free } L^{a} \\
\text { Free } B^{b} \\
M^{c} L \\
M B\end{array}$ & $\begin{array}{l}8.57 \pm 0.16 \\
8.11 \pm 0.09 \\
8.12 \pm 0.11 \\
8.01 \pm 0.18\end{array}$ & $\begin{array}{l}8.42 \pm 0.13 \\
7.83 \pm 0.12 \\
8.15 \pm 0.21 \\
8.03 \pm 0.09\end{array}$ & $\begin{array}{l}8.02 \pm 0.07 \\
6.82 \pm 0.13 \\
8.10 \pm 0.17 \\
7.98 \pm 0.15\end{array}$ & $\begin{array}{l}7.51 \pm 0.14 \\
6.11 \pm 0.09 \\
8.10 \pm 0.18 \\
7.98 \pm 0.11\end{array}$ & $\begin{array}{l}6.57 \pm 0.12 \\
5.89 \pm 0.14 \\
8.03 \pm 0.20 \\
7.90 \pm 0.14\end{array}$ \\
\hline
\end{tabular}

$\mathrm{aL}=$ Lactobacillus acidophilus + Lactobacillus casei.

$\mathrm{b}_{\mathrm{B}}=$ Bifidobacterium longum + Bifidobacterium bifidum

$\mathrm{cM}=$ microencapsulated.

ulated gastric acid fluid and bile salt conditions after storage are shown in Figure 4 and Figure 5. The optimized probiotic microcapsules produced the highest viable cell counts for both Lactobacillus spp and Bifidobacterium spp under the SGFT after storage than those prebiotics-free counterparts. Probiotic counts for the optimized microcapsules remained at $10^{5}$ to $10^{6} \mathrm{CFU} / \mathrm{g}$ after $8 \mathrm{wk}$ of storage, relative to only $10^{2}$ to $10^{3} \mathrm{CFU} / \mathrm{g}$ survival for the $1 \%$ and $3 \%$ alginate counterparts. However, both Lactobacillus spp and Bifidobacterium spp showed a decrease of 1 log cycles compared with the initial cell counts (Figure 3) without significant differences among 3 treatments. The survival of microorganisms is affected by the low $\mathrm{pH}$ of the environment. Hook and Zottola (1988) reported that $L$. acidophilus showed a rapid decline in numbers at $\mathrm{pH} 2.0 \mathrm{~m}$ and most strains of bifidobacteria were sensitive to $\mathrm{pH}$ values below 4.6. Our results demonstrated that microencapsulation with sodium alginate and prebiotics could provide good protection for probiotics under the gastric acid fluid test.

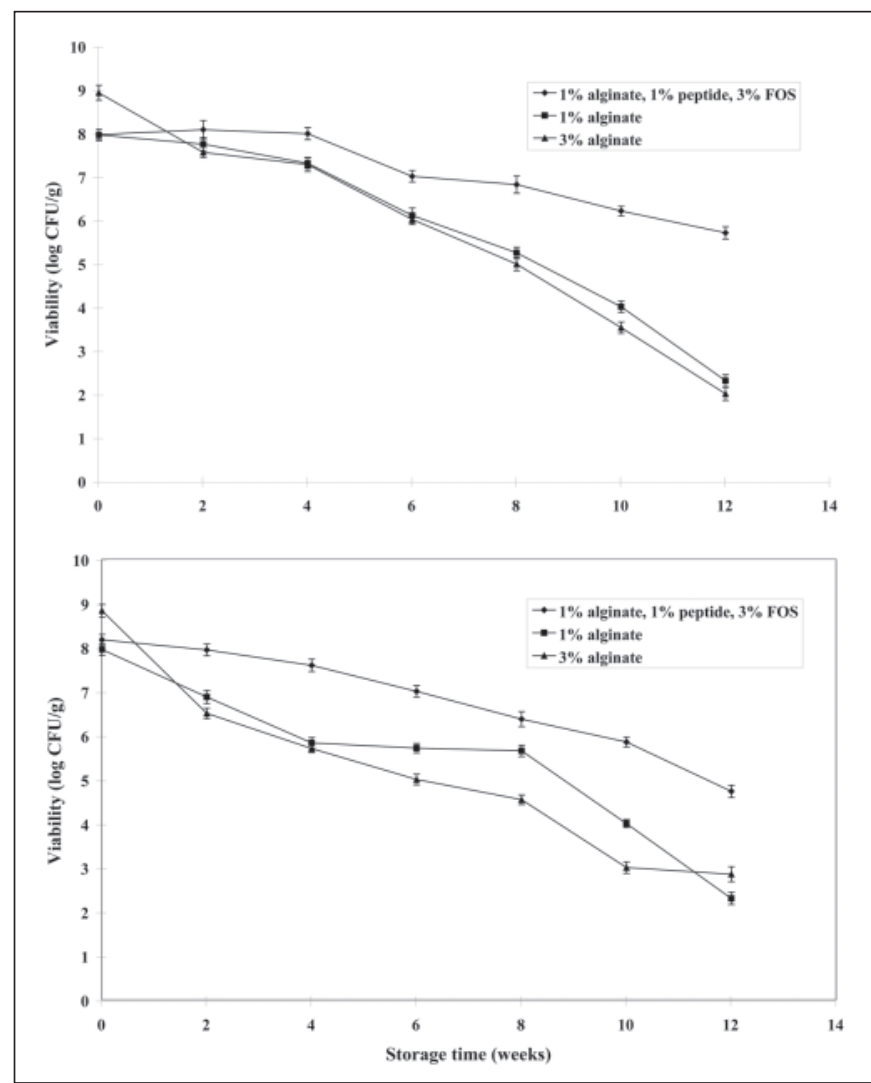

Figure 3-Survival of microencapsulated Lactobacillus and Bifidobacterium in distilled water for 12 wk of storage with 3 different microcapsule formulations.
The results of our preliminary test and other studies (Chou and Wimer 1999; Vinderola and Reinheimer 2003) showed that probiotics had higher tolerance to acid than to bile salts. In this sense, it is generally considered necessary to evaluate the ability of potentially microencapsulated probiotic bacteria to resist the effect of bile salts. Probiotic counts for the optimized microcapsules remained at $10^{5}$ to $10^{6} \mathrm{CFU} / \mathrm{g}$ after $8 \mathrm{wk}$ of storage, relative to only $10^{2}$ to $10^{3}$ $\mathrm{CFU} / \mathrm{g}$ survival for the $1 \%$ and $3 \%$ alginate counterparts, which is similar to the results of under the SGFT. Both Lactobacillus spp and Bifidobacterium spp showed a decrease of 1 log cycle compared with the initial cell count (Figure 3 ).

The results of this study concluded that the alginate gel concentrations between $1 \%$ to $3 \%$ were not a significant factor to the survival of the microencapsulated probiotics under 3 mo of storage,

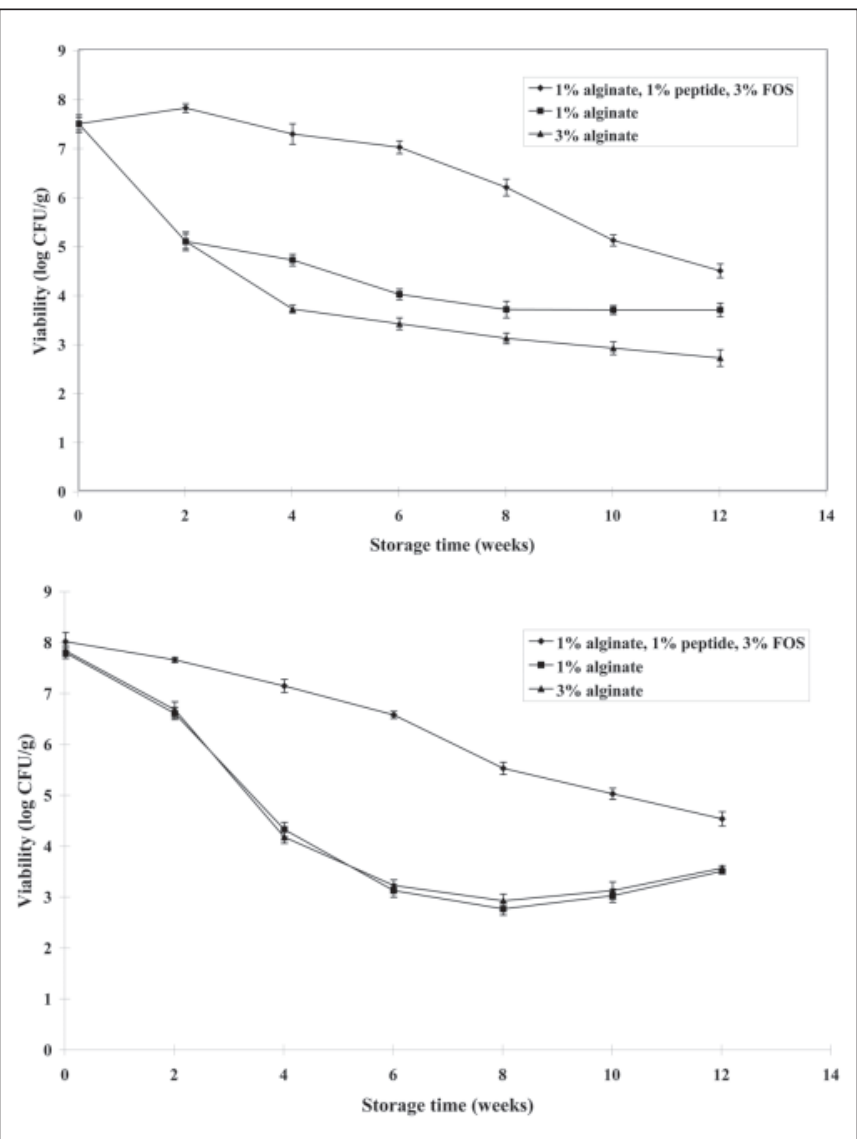

Figure 4-Survival of encapsulated Lactobacillus and Bifidobacterium in distilled water after 12 wk of storage and followed by testing in simulated gastric fluid with 3 different microcapsule formulations. 
whereas incorporating prebiotics and peptides in addition to sodium alginate as coating materials significantly increased the survival of the microencapsulated probiotics during storage.

\section{Conclusions}

$\mathrm{O}$ ptimization results indicated that $1 \%$ sodium alginate mixed with $1 \%$ peptide and $3 \%$ FOS as coating materials would produce the highest survival in terms of probiotic count. The verification experiment yielded a result close to the predicted values, with no significant difference $(P>0.05)$. The storage results also demonstrated that the addition of prebiotics in the walls of probiotic alginate microcapsules provided improved protection for the active organisms. These probiotic counts remained at $10^{6}$ to $10^{7} \mathrm{CFU} / \mathrm{g}$ for microcapsules stored for 1 mo and then treated in SGFT and bile salt test.

\section{Acknowledgments}

The authors wish to thank National Science Council in Taiwan for their support of this research.

\section{References}

Adhikari K, Maustapha A, Frun IU, Fernando L. 2000. Viability of microencapsulated bifidobacteria in set yogurt during refrigerated storage. J Dairy Sci

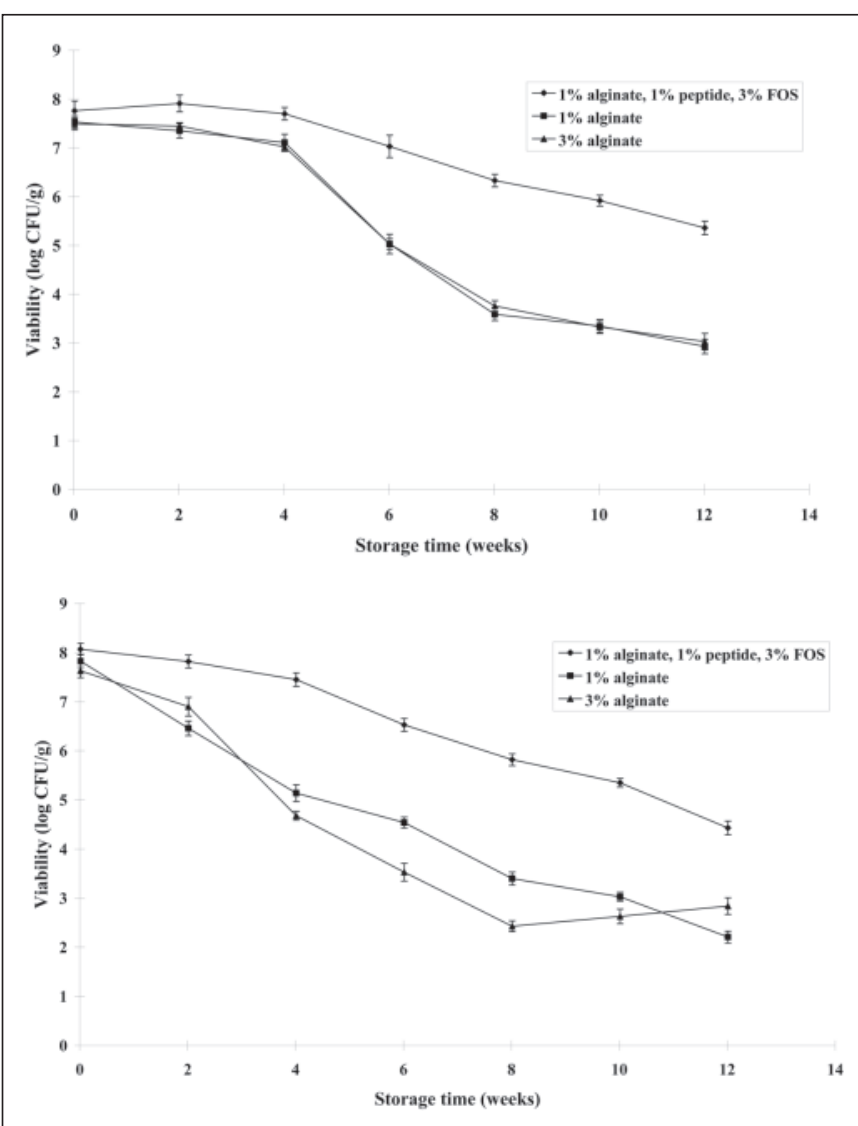

Figure 5-Survival of encapsulated Lactobacillus and Bifidobacterium in distilled water after 12 wk of storage and followed by testing in simulated bile salts with 3 different microcapsule formulations.
83:1946-51.

Bielecka M, Biedrzycka E, Majkowska A. 2002. Selection of probiotics and prebiotics for symbiotic and confirmation of their in vivo effectiveness. Food Res Int 35:125-31.

Box GEP, Behnkin EW. 1960. Some new three level designs for the study of quantitative variables. Technometrics 2:455-75.

Champagne CP, Gaudy C, Poncelet D, Neufeld RJ. 1992. Lactococcus lactis release from calcium alginate beads. Appl Environ Microbiol 58:1429-34.

Chandramouli V, Kailasapathy K, Peiris P, Jones M. 2004. An improved method of microencapsulation and its evaluation to protect Lactobacillus spp in simulated gastric conditions. J Microbiol Meth 56:27-35.

Chen MJ, Chen KN, Lin CW. 2003. Optimization of the viability of probiotics in a new fermented milk drink by genetic algorithms for response surface modeling. J Food Sci 68:632-8.

Chen MJ, Chen KN, Lin CW. 2004. Optimization of the viability of probiotics in a fermented milk drink by the response surface model. Asian-Aust J Animal Sci 17:705-11

Chou L, Weimer B. 1999. Isolation and characterization of acid- and bile-tolerant isolates from strains of Lactobacillus acidophilus. J Dairy Sci 82:23-31.

Dave RI, Shah NP. 1998. Ingredient supplementation effects on viability of probiotic bacteria in yogurt. J Dairy Sci 81:2804-16.

Fooks LJ, Fuller R, Gibson GR. 1999. Prebiotics, probiotics and human gut microbiology. Int Dairy J 9:53-61.

Fuller R. 1992. Probiotics: the scientific basis. London: Chapman \& Hall. p 125.

Gibson GR, Roberfroid MB. 1995. Dietary modulation of the human colonic microbial: introducing the concept of prebiotics. J Nutr 125:1401-12.

Gilliland SE. 1989. Acidophilus milk products: a review of potential benefits to consumers. J Dairy Sci 72:2483-94.

Hansen LT, Allan-Wojtas PM, Jin YL, Paulson AT. 2002. Survival of Ca-alginate microencapsulated Bifidobacterium spp in milk and simulated gastrointestinal conditions. Food Microbiol 19:35-45.

Hegenbart S. 1993. Encapsulated ingredients keep problems conversed. Food Prod Des 3:28-34.

Hook SK, Zottola EA. 1988. Effect of low pH on the ability of Lactobacillus acidophilus to survive adhere to human intestinal cells. J Food Sci 53:1514-6.

Iwana H, Masuda H, Fujisawa T, Suzuki H, Mitsuoka T. 1993. Isolation and identification of Bifidobacterium ssp. in commercial yogurt sold in Europe. Mitsuokifidobact Microflora 12:39-45

Krasaekoopt W, Bhandari B, Deeth H. 2003. Evaluation of encapsulation techniques for probiotics for yogurt. Int Dairy J 13:3-13.

Krasaekoopt W, Bhandari B, Deeth H. 2004. The influence of coating materials on some properties of alginate beads and survivability of microencapsulated probiotic bacteria. Int Dairy J 114:737-43.

Lacroix C, Paquin C, Arnaud JP. 1990. Batch fermentation with entrapped growing cells of Lactobacillus casei. I. Optimization of the rheological properties of the entrapment. Appl Microbiol Biotechnol 32:403-8.

Lapierre L, Undel P, Cox LJ. 1992. Lithium chloride-sodium propionate agar for the enumeration of bifidobacteria in fermented dairy products. J Dairy Sci 75:1192-6.

Lee J, Ye L, Landen WO, Eitenmiller RR. 2000. Optimization of an extraction procedure for the quantification of vitamin $\mathrm{E}$ in tomato and broccoli using response surface methodology. J Food Composit Anal 13:45-57.

Lin CW, Chen HL, Liu JR. 1999. Identification and characterization of lactic acid bacteria and yeasts isolated from kefir grains in Taiwan. Aust J Dairy Technol 54(1):14-8.

Lourens-Hattingh A, Viljoen C. 2001. Yogurt as probiotic carrier food. Int Dairy J 11:1-17.

Mattila-Sandholm T, Myllarinen P, Crittenden R, Mogensen G, Fonden R, Saarela M. 2002. Technological challenges for future probiotic foods. Int Dairy J 12:173-82.

Mitsuoka T, Hidaka H, Eida T. 1987. Effect of oligosaccharides on intestinal microflora. Die Nahrung 31:427-36.

Prevost H, Divies C. 1988. Continuous prefermentation of milk by entrapped yogurt bacteria. I. Development of the process. Milchwissenschaft 43:621-5.

Schillinger U. 1999. Isolation and identification of lactobacilli from novel-type probiotic and mild yogurts and their stability during refrigerated storage. Int J Food Microbiol 47:79-87.

Shah NP, Lankaputhra WEV. 1997. Improving viability of Lactobacillus acidophilus and Bifidobacterium ssp. in yogurt. Int Dairy I 7:349-56.

Shah NP, Ravula RR. 2000. Microencapsulation of probiotic bacteria and their survival in frozen fermented dairy desserts. Aust J Dairy Technol 55:139-44.

Sheu TY, Marshall RT. 1993. Microentrapment of lactobacilli in calcium alginate gels. J Food Sci 54:557-61.

Sultana K, Godward G, Reynolds N, Arungaswamy R, Peiris P, Kailasapathy K. 2000. Encapsulation of probiotic bacteria with alginate-starch and evaluation of survival in simulated gastrointestinal conditions and in yoghurt. Int J Food Microbiol 62:47-55.

Vinderola CG, Reinheimer JA. 2003. Lactic acid starter and probiotic bacteria: a comparative "in vitro" study of probiotic characteristics and biological barrier resistance. Food Res Int 36:895-904.

Weng W, Liu W, Lin W. 2001. Studies on the optimum models of the dairy product Kou Woan Lao using response surface methodology. Asian-Aust J Animal Sci 14:1470-6. 